\title{
Strange Animals, and What to Do with Them
}

\author{
TORBEN ALBERTSEN
}

\begin{abstract}
In Chile, intercultural education, at least ideally, is concerned with the learning from indigenous people, and as such, anthropology is at the center stage. One of the aspects learning might learn from anthropology has to do with plurality, and more specifically, how to embrace plurality without reducing it at the same time. If sustainability has any stake in this, it would have to do with learning how to continually sustain plurality. Viveiros De Castro is a founding part of a relatively recent anthropological tradition called recursive anthropology, sometimes also referred to as the ontological turn. His ethnography consists of a proposal for Amerindian cosmology and his methodology proposes a way to sustain plurality. I propose to treat both aspects. First, we would like to describe his Amerindian cosmology, and we are specifically here interested in its different approach to nature. Secondly, we will describe his methodology in its relation to his ethnography, and here we will be specifically concerned with thinking his method as a pedagogical project involved with intercultural learning.
\end{abstract}

KEYWORDS: plurality, anthropology, Amerindian, intercultural, learning

Jaguars are strange animals. They eat juicy steaks and drink beer when flowing from the body of their victims instead of the raw meat and blood we would normally suppose. These are some of the strange ideas that Viveiros de Castro's anthropology proposes when trying to unravel Amerindian thought (Viveiros De Castro, 1992, 1998, 2004A, 2004B, 2010, 2012, 2013, 2014). With the word Amerindian he is referring principally to Amazonian indigenous people as well as some north American Indigenous people. The correct phrase is perspectivism which is reminiscent to what has been understood as animism. Viveiros De Castro however, introduces another concept, multinaturalism, which would be the Amerindian contrast to what we in the west tends to understand as multiculturalism. The paper relates the title part of "strange animals" to his perspectivism while retaining the other part, "what to do with them" for his concept of multinatualism. The reason for this, I will argue, can be found in his method, which simultaneously is related to the second part of the title. This second part is also related to his proposal as a founding part of the relatively recent anthropological tradition often called 'recursive anthropology', or sometimes also 'the ontological turn'. In summary, perspectivism (strange animals) is a description of his principal ethnography (Viveiros De Castro, 1992, 1998, 2004B, 2012) while multiculturalism (what to do with them) is his recursive response or methodological contribution, and also, where he tries to go beyond anthropology as an autonomous field of expertise on Amerindian people. 


\section{Perspectivism}

In Amerindian cosmologies there is no creation ex nihili. Everything is a transformation from something else. Furthermore, the original common condition is not animality or nature like in our evolutionist biology, but rather humanity. Animals, therefore, are former humans, and not humans' former animals (Viveiros De Castro, 1998, 2012).

Perspectivism is ontology which postulates the social character of relations between humans and non-humans (Viveiros De Castro 1998). It is based on a relationship between a kind of life principle (soul, spirit, culture, ect.) on the one hand and nature or the body on the other. This does not however surmount to a metaphysical dualism. First, an internal principle which is anthropomorphic in character and which every animated being poses, being traced from the original condition of humanity. This principle is formally the same in all animate beings, although is generally attributed to animals or nature of a more symbolic character, that is, what has a relevant symbolic function for the society at hand.

Secondly, while this internal principle is given to all, nature or the body is something made. Bodies in this sense constitute the variable between species and also with regards to perspectives. A body constitute so to speak the differences instead of the similarities and is the fundamental difference in any point of view or perspective, precisely because the condition of a perspective is that it is located in a body. While the commonality of the internal principle gives all beings the same conceptual and anthropomorphic repertoire, the body where it is located makes these conceptualities differ, hence refer to different things. In this sense a Jaguar drinks blood while humans drink beer, different things, but they do so from a similar anthropomorphic conceptuality, that is, the Jaguar conceptualizes the blood in human ways, hence as beer.

The body is not given but made through metamorphosis, in the sense of a clothing that you can change. This clothing determines what you see when you see others, while the internal principle is generally hidden from view. By body he is not referring to physiological differences, but rather to what he calls affect, or the idea of dispositions or capacities, which render the body unique for example to each species. A body is an assemblage of affects or ways that constitute habitus or the subjectivizing and personifying characteristics, rather than physiological characteristics (Viveiros De Castro, 2004B, 2012).

To understand Amerindian perspectivism it is important to de-essentialize or de-center the subject so to speak in favor of the point of view or perspective. For example, it is not because we are subjects that we have a perspective or a point of view, but rather, because we have a perspective or point of view that we are and become subjects. So, in a sense it is our perspective, which is situated in our bodies, that gives us our ontological status, not the ontology as essence that allows us to have a perspective.

A fish is not a fish because of some intrinsic ontology or fishiness, but is a fish only by virtue of someone else whose fish it is, or perhaps more accurately, from what perspective you see the fish. Substances named by substantives (noun) like a fish or a snake, are somehow used as if they were relational pointers that each has a potential unique point of view. And so, the cosmology is a $100 \%$ relational and has no distinction between, say, primary and secondary qualities of substances, or between say, cultural and natural facts. In this sense we have a cosmology which is both relative and universal at the same time, in a sense, it is universally relational (Viveiros De Castro, 2004B, 2012). 


\section{Deployment}

So, what kind of methodological consequences does De Castro draw from his ethnography, or, what to do with these strange animals? He proposes that instead of explaining, interpreting or rationalizing native thought we need to explicate it, deploy it, experiment with it and draw out its consequences in order to verify the effect that it might have on our own thinking (Viveiros De Castro, 2013, 2014). To deploy Amerindian thought means to put it into a dialogue with our own currents of thought and follow the implications of said perspectives.

What he means by explanation, interpretation and rationalization is to find the causes of something as in causes that are external to the thinking itself, say in historical, sociological or biological terms. He proposes that this line of thinking is often accompanied by the question of belief, which, does not permit a deployment of their thinking. Castro exemplifies this problem with a shaman that throws a magic arrow (Viveiros De Castro, 2014). If we have to orient our thinking with respect to whether we believe or not in the magic of the arrow, we are implicitly taking for granted an invariable o transcendent ground which places us in a unique third position from where we can judge the reality of both sides. Here the magic is negated as a valid reason and we tend to replace it with our own models of society (belief, power, fetishism, etc.), in other words, we see only ourselves. The question of belief, orders us to distance ourselves from whatever consequences such thinking might have and reduce it for example to metaphor, like the magic of the arrow is a metaphor for say, sociological mechanisms of control or say, Freudian mechanisms of a sexual drive, or what have you.

This is simultaneously a reduction of their problems to our problems. Instead, what is worth knowing is precisely that to which we do not know the answer, namely, what the Indians are saying when they say that fish have a human perspective. The question of belief forces us into the trap of having to believe either the native or our own theories which presents a fictive competition and dilemma and turns at best into a reduction of their worlds to ours.

\section{Multinaturalism}

So, what is his own deployment then, of Amerindian perspectivism? The concept that epitomizes this deployment is multinaturalism as a contrastive or comparative feature to what he deems our multiculturalism, which is proposed as our predominant western cosmology (Viveiros De Castro, 1998, 2004). By multiculturalism he is referring to the way we tend to see nature or the body as the unity and common condition of mankind while culture (soul, spirit, vitality, etc.) is where multiplicity and differences are found. Amerindian societies on the contrary tends to see the culture (soul, spirit, etc.) as this unifying common condition while nature and the body are where multiplicity and differences are conceived.

One of his used references is an anecdote he quotes from Levi-Strauss which was used to explain ethnocentrism (Viveiros De Castro 1998). While the Spanish inquisition and theologians were discussing whether or not the Amerindians had souls (e.g.: culture today), the natives where busy drowning white people to see if their bodies were the same as theirs. Hence both took for granted the specific location of unity and diversity. The Spanish saw the body as selfevidently similar to their own while the soul was where the question of difference was situated. The Amerindians, on the contrary, saw the soul of the white man as self-evidently similar to theirs, while placing the question of difference in the body, trying to unravel whether the white man had the same body as theirs. So, the general problem Amerindians face is to differentiate nature out of a universal sociality, or alternatively, they have one epistemology, but

278

Strange Animals, and What to Do with Them

Futures of Education, Culture \& Nature - Learning to Become 
many ontologies, where as we seem to have the inverse, many epistemologies but only one ontology or nature. A multinaturalistic cosmology propose a constant epistemology but with variable ontologies.

\section{Paedagocial perspectives}

In Latin America, embracing a 'futures in the plural', o a plurality of views on learning embedded in various worldviews is directly related to the positive representation of indigenous ideas as valid alternatives. Two aspects are especially relevant here, a more anthropological one and a radical pedagogical perspective related to intercultural learning. First the antropological, how to learn about them without reducing their ideas to our own constructions, and secondly, if this can be managed, how to actually learn from them. If indigenous worldviews are to be included in 'futures in the plural', say, as something that might help us imagine and actualize radical different forms of sustainable development, then both of these aspects need to be prioritized.

The method of Viveiros de Castro reaches for the pedagogical goal while trying to attack this problem from within an anthropological framework. To deploy something means effectively to learn from it and to be inspired by it. This deployment, however, is framed within the anthropological idea of radical difference. In Castro these differences are seen as ontologicalepistemological embedded in the cosmology (multinatural vs. multicultural). Castro uses the word equivocation rather than the word error to refer to the radical differences between systems of meaning (Viveiros De Castro, 2004A). In a methodological and hermeneutical sense equivocation tries to guarantee these differences by presupposing them. Linguistically it could be framed as the opposite of the ontological presupposition of sameness in Saussure, that is, that words stand in different forms (epistemological-structural) for the same things (ontological). Simply put, when in mapudungun a mapuche uses the word kimün ("knowledge") we cannot presuppose that he or she is referring to the same "things" or ontological reality as I am when I use the word knowledge in English. We are never actually talking about the same things or realities, even though our translations may suggest that they are similar. In this sense comparison is paramount, but only through the optics of translation. Therefore, comparison must be re-thought into the service of translation, rather than translation being in the service of comparison.

Castro is partially inspired by Deleuze, and as such, he is looking for interesting problems as opposed to dogmatic ones. In a philosophical sense it would mean trying to get inspiration and broadening our imagination from problems that are different, rather than trying to solve problems we are already familiar with. From a deleuzian perspective on learning, Castro takes indigenous concepts precisely as a kind of violence, or, that which can provoke thought through its radically different approach to reality (multinatural rather than multicultural). For Deleuze, such violence is a necessary component of learning, which to him means that the conditions of critique and the conditions of creation are the same (Deleuze, 1994, p.139). Framing his own ideas with Deleuze, Castro proposes to sustain indigenous ideas as virtualities (or concepts) indifinitly without actualizing them (Viveiros De Castro, 2014, p.14). For Castro, the actualization then becomes the process by which one seeks causes and attempts to rationalize indigenous thought, in summary, as a process that closes down indigenous problems by causal explanation, something intimately related also to the assymetries between knowledge systems. Maintaining them as virtual would mean to maintain them as a source of inspiration and imagination from the point of view of their incompatibility, without exhausting this tension in a model of causal explanation, a process he also refers to as a permanent 
decolonization of thought (Viveiros De Castro, 2010). In a sense, Indigenous thoughts are to Castro what to Deleuze is "someone not knowing what everybody knows" in his critique of the dogmatic image of thought (Deleuze, 1994, p.130).

If learning is violent, and translation is our method of comparison, then we must get a hold of the specific aspect in translation that is violent, precisely because this could help us understand the equivocations involved between different systems of thought. In Castro this is explained as the part of translation that deals with treason, that is, the treason manifested in the native language when trying to express oneself in a different language (Viveiros De Castro, 2004A, 2010, 2013). Expressing equivocal ideas such as kimün can betray and disrupt our understanding of what knowledge is and open up for new ways of understanding it, new ways of problematizing it. The functional purpose of such an anthropology and intercultural learning is precisely to multiply the agents of the world, or in other words, to think 'futures in the plural'.

\section{Literature}

Deleuze, G. (1994). Difference and Repetition. (P. Patton. Trans). New York: Columbia University Press. (Original work published 1968).

Viveiros De Castro, E. (1992). From The Enemy's Point of View. Humanity and Divinity in an Amazonian Society. (C. Howard. Trans.) Chicargo: University of Chicago Press. (Original work published 1986).

Viveiros De Castro, E. (1998). Cosmological Deixis and Amerindian Perspectivism. The Journal of the Royal Anthropological Institute, 4(3), 469-488.

Viveiros De Castro, E. (2004A). Perspectival Anthropology and the Method of Controlled Equivocation. Tipiti: Journal of the Society for the Anthropology of lowland South America. 2(1): 3-22.

Viveiros De Castro, E. (2004B). "Exhanging Perspectives: The Transformation of Objects into Subjects in Amerindian Ontologies." Common knowledge, vol 10, Issue 3 Fall pp. 463-484

Viveiros De Castro, E. (2010). Metafísicas caníbales, líneas de antropología postestructural. Madrid: Katz Editores.

Viveiros De Castro, E. (2012). Cosmological perspectisim in Amazonia and elsewhere. Masterclass series 1. Manchester: HAU Network of Ethnographic Theory.

Viveiros De Castro, E. (2013). The Relative Native. Journal of Ethnographic Theory 3(3). 473502.

Viveiros De Castro. (2014). Who is afraid of the ontological wolf? Some comments on an ongoing anthropological debate. CUSAS Annual Marilyn Strathern Lecture. Retrieved from https://sisu.ut.ee/sites/default/files/biosemio/files/cusas strathern lecture 2014.pdf 